Evolution and Human Nature

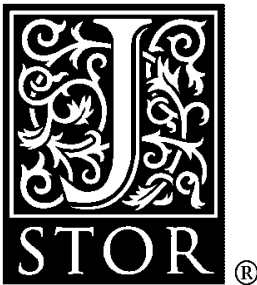

\author{
Arthur J. Robson
}

The Journal of Economic Perspectives, Vol. 16, No. 2. (Spring, 2002), pp. 89-106.

Stable URL:

http://links.jstor.org/sici?sici=0895-3309\%28200221\%2916\%3A2\%3C89\%3AEAHN\%3E2.0.CO\%3B2-4

The Journal of Economic Perspectives is currently published by American Economic Association.

Your use of the JSTOR archive indicates your acceptance of JSTOR's Terms and Conditions of Use, available at

http://www.jstor.org/about/terms.html. JSTOR's Terms and Conditions of Use provides, in part, that unless you have obtained prior permission, you may not download an entire issue of a journal or multiple copies of articles, and you may use content in the JSTOR archive only for your personal, non-commercial use.

Please contact the publisher regarding any further use of this work. Publisher contact information may be obtained at http://www.jstor.org/journals/aea.html.

Each copy of any part of a JSTOR transmission must contain the same copyright notice that appears on the screen or printed page of such transmission.

The JSTOR Archive is a trusted digital repository providing for long-term preservation and access to leading academic journals and scholarly literature from around the world. The Archive is supported by libraries, scholarly societies, publishers, and foundations. It is an initiative of JSTOR, a not-for-profit organization with a mission to help the scholarly community take advantage of advances in technology. For more information regarding JSTOR, please contact support@jstor.org. 


\title{
Evolution and Human Nature
}

\author{
Arthur J. Robson
}

$\mathbf{F}$

rom an economic perspective on individual decision making, human beings have three key characteristics: preferences, beliefs and rationality. Beliefs are the probabilities with which people think various outcomes will occur, conditional on information that might be available. Preferences are the rankings over the set of gambles that are based on such beliefs over the outcomes. Rationality is the extent to which people succeed in choosing optimal actions in the light of their beliefs and preferences and the extent to which their beliefs are appropriately modified by their information.

Economists typically impose only rather weak assumptions on preferences. For example, preferences are taken to be transitive and, sometimes less explicitly, exogenous and unchanging. Stronger assumptions are typically imposed on preferences in specific contexts, however. For example, preferences over time might be represented by an additively separable function with constant rate of discount, despite widespread recognition that this case is a special one. Further, attitudes to risk are often represented by the expected utility theorem, which rests on assumptions that are strong, if also appealing. The assumptions made on rationality, in particular, are usually very strong. That is, rationality in economic models usually entails the exact optimization of preferences and modification of beliefs in accordance with Bayes' theorem.

The economist's basic picture of preferences, beliefs and rationality has been subject to challenges from a growing number of empirical anomalies. The proposed explanations of these anomalies involve relaxing the assumptions that economists make on these preferences, beliefs or rationality. For example, preferences

- Arthur J. Robson is Professor of Economics, University of Western Ontario, London, Ontario, Canada. His e-mail address is 〈arobson@uwo.ca〉. 
may be subject to time inconsistency: a person might prefer to receive $\$ 105$ a year and a day from now instead of $\$ 100$ a year from now, but that same person might prefer to receive $\$ 100$ today rather than $\$ 105$ tomorrow. This example is inconsistent not merely with the simple additively separable model of preferences over time, but with a wide range of generalizations. Further, there is a vast literature on alternatives to the expected utility theorem. Much of this is motivated by the "Allais paradox" and suggests that attitudes toward risk cannot be captured by simply weighting utility outcomes with probabilities, as in expected utility, but rather that these probabilities should be introduced in a nonlinear fashion (Machina, 1982, for example). As a final example, bounds on rationality become evident when individuals demonstrate that they cannot see through complex stochastic chains of events to the ultimate outcomes (for example, Gabaix and Laibson, 2000).

Although many of these challenges to the common assumptions of economists have merit, it can be difficult to differentiate large, systematic anomalies from those anomalies that are either small or artifacts of particular atypical experiments. This situation begs for a unified treatment. This paper argues that consideration of the biological evolution of preferences, beliefs and rationality can provide such a treatment. ${ }^{1}$ When relevant, the paper focuses on hunter-gatherer societies as the evolutionary setting, since some such society characterizes all two million years of human history, excepting only the 10,000 years since the advent of agriculture. Of course, there is no assurance that behavior shaped like this remains biologically appropriate in modern societies, which are quite different from hunter-gatherer societies.

Consideration of the likely biological origins of economic behavior provides, in particular, a basis for assessing the importance of empirical anomalies. In some cases, the theory of biological evolution provides strong support for a standard economic theory of individual behavior. In other cases, evolution may suggest alternative unexpected directions. In general, an evolutionary basis helps to maintain constraints on economic theory. Moreover, an evolutionary explanation for individual behavior helps maintain the key analytical advantage that economics has over the other social sciences-that of being based on an overarching theory.

Each of the three key characteristics-preferences, beliefs and rationality-is examined in turn. Preferences, including those over time and uncertainty, are given more attention than are beliefs and rationality. At first blush, preferences are the most obvious feature of economic behavior that would be influenced by biological evolution. On reflection, although the effect of biological evolution on rationality must also have been profound, it is less clear how to proceed in studying this. There is a small but growing literature on the biological shaping of preferences; there is less on the shaping of beliefs and rationality. Thus, although the treatment of preferences can be, in tone, an informal survey of the literature, the

\footnotetext{
${ }^{1}$ References and more details on some aspects of the first and last of these topics are in Robson (2001a).
} 
treatments of beliefs and rationality represent, to a larger extent, suggestions for future research.

These three characteristics are viewed as the joint outcome of a principal-agent problem, where Nature is the principal and the individual is the agent. Nature will be shamelessly anthropomorphized here, for the sake of vividness and conciseness. Thus, when we say that "Nature wishes" the individual to maximize biological fitness, this is shorthand for claiming that individuals who maximize fitness will ultimately dominate the population. That is, biological fitness is closely linked to the number of offspring.

Nature may well be "better informed" than are individuals about some aspects of biological fitness, such as that good health requires an adequate number of calories. However, individuals may well have better information about local circumstances, such as the likelihood that food is available at a particular time and place. The present evolutionary explanations of key characteristics of individual behavior build on this distinction. In particular, it is argued that Nature may have encoded consumption outcomes in the brain as varying intensities of pleasure, but allowed beliefs to be shaped by local information, and left ultimate decisions to be made flexibly and rationally by the individual.

It is intriguing that this notion of Nature and individual choice locked together in the decision-making process mirrors some structural features of the brain. The limbic system, a part of the brain implicated in instinct and feeling, is an evolutionarily ancient part of the brain and is present in a similar form in many animals. In contrast, the frontal lobes, which are implicated in conscious decision making, are greatly enlarged in primates in general and in humans in particular. Neural pathways permit the transfer of appropriate signals about various outcomes from the limbic system to the frontal lobes when these weigh alternative actions. ${ }^{2}$

The working hypothesis adopted here, for the most part, is that biological evolution has encouraged fitness of the individual rather than fitness at any higher or lower level. There are a number of reasons to be cautious about this hypothesis. One would seem to be that it could conflict with the interests of the group or species. However, especially given that human beings are capable of complex behavior, there are often ways to reap the social gains from cooperation without creating a conflict with the interest of the individual. For example, if the prisoner's dilemma is infinitely repeated, cooperation may be sustained by means of a "tit-for-tat" Nash equilibrium strategy of matching an opponent's last choice. In such cases, where each member of a group of cooperators also acts in her own best interest, the question of whether to focus on the individual or the group is less pressing.

More potentially problematic than the question of individual versus group

\footnotetext{
${ }^{2}$ The decision-making system outlined here may not be reliant on consciousness, however. Perhaps the experience of pleasure in humans is the means by which the limbic system communicates with consciousness (Le Doux, 1996).
} 
selection is that biological evolution may alternatively be viewed as bearing on genes (Dawkins, 1982). Evidence reinforcing this view is that genes can be detrimental to the interest of the individual, as in the case of sickle-cell anemia. ${ }^{3}$ However, although a large number of genes is likely to influence in a complex way any economically significant behavior, not much is known about how such genetic effects on behavior operate. The discussion in this paper will sometimes refer to gene selection arguments, but the primary focus will be on the individual selection hypothesis. Moreover, since the individual approach seems consistent with the usual stance in economics that individuals are selfish, this alternative also seems the likeliest to conserve existing economic theory.

\section{Preferences}

\section{Why is There Utility at All? Why is it Defined on Intermediate Goods?}

All animals must react in a variety of situations, thus influencing their ultimate biological success. Animals with the best repertoire of instinctive and learned procedures for making these choices would be favored by evolution. Some of these choices are clear-cut-for example, it is usually advantageous to avoid bodily injury. Fear and pain are accordingly strong enough instinctive responses that they usually override other considerations. Even in more complex decision-making situations, certain elements may have clear, if undramatic, implications. For example, consuming certain combinations of food might typically be advantageous.

In seeking to maximize biological fitness, Nature has an incentive to orchestrate optimal choice by the individual among consumption bundles. The first question that might arise is then: Why might Nature embed rankings over consumption goods rather than over offspring themselves, since consumption goods are only intermediate goods to the final goal of producing offspring, from an evolutionary point of view?

Such ranking of consumption goods, rather than direct ranking over offspring, is optimal since Nature knows more about the connection of consumption to offspring than any human-at least for most of human history. If

\footnotetext{
${ }^{3}$ Sickle-cell anemia is discussed, for example, by Cavalli-Sforza and Bodmer (1999, pp. 139-154). Human beings inherit two copies of any gene-one from each parent. Consider a population with a number of "normal" genes and a number of a variant type associated with this anemia. Individuals who inherit two copies of the variant gene (who are "homozygous" for it) are subject to severe anemia and have much lower fitness; those with a single copy (who are "heterozygous") are only mildly anemic and seem to have enhanced resistance to malaria. From the point of view of the variant gene, the advantages derived from the heterozygous carriers may outweigh the disadvantages from the homozygous carriers. However, each homozygous individual sees only the disadvantages.

Benevolence toward close relatives could also be viewed in this light. The theory of "kin selection" implies that I would help my brother, for example, despite a cost to myself, if the benefit to him were large enough. This stems from the possibility that my brother and I share the same gene. Bergstrom (1996) shows how this theory helps explain family economic interactions.
} 
one consumption choice typically leads to greater production of offspring, this linkage is known to Nature from Nature's observation of many of the individual's ancestors. On the other hand, it is impossible for a particular individual to derive this same assurance from personal experience or from directly observing the experience of others nearby. Compared to other species like rabbits or fruit flies, and especially in recent times, the expected number of offspring of each human is small. An individual who relies on personal experience might then, for example, observe one relative who has an unhealthy diet, but still lives a long life with relatively many offspring, and another relative who consumes a healthy diet, but dies early with no children. Because individuals see only a small sample, requiring them to learn what consumption choices lead to more offspring will be less effective than having them adhere to the ranking of these choices set by Nature.

This argument suggests a general explanation of why it might pay for evolution to embed rankings for outcomes that, from a biological point of view, are intermediate rather than final. More specifically, it provides a defense for defining individual preferences over consumption, as economists usually do.

Given that rankings are over consumption bundles, an evolutionary argument in favor of a utility function, in particular, is that it may outperform some of the obvious alternatives. For example, suppose there are a number of possible consumption bundles, $N$. One alternative is that Nature might seek to dictate the better bundle directly, for each individual, from each pair of bundles. But this process would involve specifying one alternative from each of a very large number of pairs. The use of a utility function, on the other hand, involves Nature assigning utilities based on biological fitness to each consumption bundle and then having individuals choose the consumption bundle with higher utility.

What matters is the relative cost of the computations needed under each scenario. Implementing a more costly alternative would require a larger brain and therefore greater metabolic energy resources for building and maintaining this organ. Such resources would have to be diverted from other applications-building the body, for example-that otherwise enhance fitness. Thus, such costs are ultimately denominated in fitness terms.

How then do the costs of the two alternatives compare? The utility approach may involve a cost for each assignment of utility to a consumption bundle. It may also involve a fixed cost for the extra cognitive capacity needed for individuals to compare utilities and to choose the appropriate bundle. However, the overall cost of the utility function approach only increases in a linear fashion, as the number of possible consumption bundles becomes large. On the other hand, if Nature dictated the better of each pair of bundles, without recourse to utility, there might be some neural cost for each such pair. Since the number of pairs grows more quickly than does the number of bundles, as the number of bundles increases, it follows that the cost of this alternative also grows more quickly than the number of 
bundles. Thus, the use of a utility function is preferred whenever there are sufficiently many bundles. ${ }^{4}$

\section{Time Preference}

Economists typically assume that people have a preference for consumption in the present over consumption in the future. An evolutionary perspective suggests reasons for such economic time preference.

Rogers (1994) presents one biological model of the formation of such time preference. His model focuses on the possibility of shifting resources from oneself now to one's offspring later. Consider an individual female who faces such a choice. To simplify matters, one option is that she can convert present consumption into current fertility. A second option is that she can wait a generation and increase the consumption of her daughter, who will then be the same age as she is now and so will have the same fertility function. ${ }^{5}$ However, the mother values her daughter's offspring at only one-half the value of her own offspring, essentially because sex dilutes the genes that are transmitted from mother to child with those of the father.

Thus, because offspring are only half-relatives under sexual reproduction, there is a biological basis for impatience. The mother prefers consuming now, to increase her own offspring, to passing an equal amount of consumption to her daughter later, to increase her daughter's offspring. However, if she could receive a high enough rate of return for saving, then passing consumption to the future would pay, because this would increase the number of grandchildren by enough to make up for their being more distant relatives. In such a framework, Rogers (1994) derives a rate of time preference of about 2 percent per year, an empirically reasonable value. ${ }^{6}$

Another evolutionary argument bearing on impatience concerns whether, when other things are equal, an individual would prefer to have children earlier or later. Given that each individual has more than one offspring on average (so that positive population growth occurs), a faster rate of growth can be achieved by having these offspring sooner. Hence, those types who have children younger will tend to dominate the population over time, yielding an evolutionary preference for earlier rather than later.

What biological arguments imply about time preference over economic commodities may be complicated unless current expected offspring is a function only of current consumption, as in the first example. Moreover, the relationship between expected offspring and the consumption stream may be indirect. For exam-

\footnotetext{
${ }^{4}$ Robson (2001b) offers a related but distinct argument on the desirability of embedding a utility function in each individual.

${ }^{5}$ Suppose the mother is beyond reproductive age herself at this later date, so that there is no question of her retaining this consumption then.

${ }^{6}$ In this simplification of Rogers's (1994) argument, the overall fitness for the mother is $u\left(c_{0}\right)+$ $u\left(c_{1}\right) / 2$. The equivalent economic criterion would be $u\left(c_{0}\right)+e^{-\rho T} u\left(c_{1}\right)$, where $\rho$ is the rate of time preference. Comparing the two criteria, it follows that $\rho=\ln 2 / T$.
} 
ple, waiting until an adult has built up a substantial level of total consumption, and hence a substantial body size, may enhance the prospects of her children surviving and having their own offspring.

Nevertheless, the above arguments suggest that it is promising to explain time preference in terms of biological evolution. Indeed, they go further and suggest how the standard economic formulation of a constant discount rate over time might be defended. Such a fixed discount rate over time has been called into question by the theory of "hyperbolic discounting" (Loewenstein and Prelec, 1992). This theory accounts for situations in which the discount rate apparently declines with time into the future, where preferences are always defined relative to a changing present date. As a result, a certain tradeoff over two distinct periods may seem advantageous at a early date when a low discount rate applies, but this tradeoff may be reversed at a later date when a higher discount rate applies. If offered a choice between three bottles of wine in 100 days or four bottles in 101 days, a person might be willing to wait the extra day. However, if 100 days have passed, and the same person is offered three bottles today or four bottles tomorrow, she might choose to take the wine offered now. Most basically and generally, that is, the individual has "time-inconsistent" preferences in the sense of Strotz (1956).

Direct evolutionary models of the formation of time preference typically induce time consistency. A basic and general argument, going beyond the earlier examples, is the following: Suppose that maximizing lifetime fitness, considered from an initial viewpoint, entails a particular intertemporal tradeoff over two dates in the future. When both these dates are closer and a choice must be made involving them, Nature should choose current preferences such that this tradeoff is unaffected. Otherwise, that is, the population would be subject to "invasion" by a type that maximized lifetime fitness.

On the other hand, Samuelson and Swinkels (2000) present an ingenious evolutionary argument that time inconsistency may arise in an indirect way. In a principal-agent setting like that here, Nature should trust the individual to make an appropriate judgment if the rewards are distant and various intervening circumstances must be considered. However, Nature would be more certain of the right choice between the same rewards if these were immediate. Overall, while an evolutionary argument seems to lean toward time-consistent behavior and against the hyperbolic discounting hypothesis, this topic is an intriguing one for further exploration. ${ }^{7}$

\section{Attitudes toward Risk}

The expected utility theorem occupies a central place in the economic theory of attitudes toward risk. Under this theorem, the individual evaluates gambles in terms of the expectation, derived from a given probability distribution, of the utilities of the various outcomes.

\footnotetext{
${ }^{7}$ Angeletos et al. (2001) is an account of hyperbolic discounting that is favorable to this hypothesis.
} 
What can be said about how evolution might affect attitudes toward risk? At first blush, it might seem that evolution would produce preferences satisfying the expected utility theorem. Suppose an individual must choose among a number of economic gambles over consumption bundles, where the biological consequence, in terms of expected offspring, of each bundle is the same across all gambles. If all the economic and biological risk here is independent across individuals, evolution favors the choice of the gamble that leads to the highest expected offspring overall. Moreover, the expected offspring of each gamble can also be viewed in economic terms as expected utility, where the utility of each consumption bundle is the expected offspring it produces.

However, this view of the expected utility theorem is heavily reliant on the underlying assumption that all risks are independent, and this assumption is not compelling in this setting. Consider the following example drawn from Robson (1996). Suppose there are two types of individual within a given population and, for simplicity, there are initially a large and equal number of individuals of each type. The first type has one offspring with probability $1 / 2$ and two offspring also with probability $1 / 2$, and each individual obtains an independent draw with these probabilities. It is as if each individual has a private fair coin to flip, with heads yielding one offspring and tails yielding two. The second type also generates one offspring with probability $1 / 2$ and two offspring with probability $1 / 2$. However, all individuals of this type in a given generation experience the same outcome. It is as if a single public fair coin governs all these individuals, and the draws are now independent only across generations. Again, heads yields one offspring and tails yields two.

One's first impulse might be to predict that there should be little to choose between these two types in terms of long-run evolutionary success. Indeed, the two types are tied in terms of expected population size at all dates. In both cases, the expected population size at time $T$ is $(3 / 2)^{T}$ times the original size, or, equivalently, the expected growth factor up to time $T$ is $(3 / 2)^{T}$.

Nevertheless, the second, or "public-coin," type will be dominated by the first, or "private-coin," type in the long run. How can this be reconciled with the fact that the two types have the same expected population size at every date? Under the present assumptions, the "law of large numbers" implies that there is no uncertainty about the growth factor of the private-coin type up to any given date in the future. For the public-coin type, the growth factor up to any given date is a random variable, dependent on the number of times that the public coin comes up tails. The extremes of the distribution of this variable loom large in terms of determining its expectation. When one considers all of the possible outcomes for the public-coin type and takes an expectation of its growth factor, it is the same as the certain growth factor for the private-coin type. But as $T$ gets larger, the expected growth factor for the public-coin type continues to be held up by increasingly remote possibilities of increasingly enormous outcomes, those outcomes where the public 
coin came up tails in a large fraction of the time periods. ${ }^{8}$ As the number of periods becomes large, the probabilities of these very large outcomes vanish, and the remaining cases, with a lower average because they leave out the top outliers, govern the growth of the population. ${ }^{9}$

It follows that the evolutionarily optimal attitudes toward risk do not depend simply on the selfish effects of gambles, but also on whether those gambles have outcomes that are shared by others. Other things equal, gambles that are idiosyncratic, where these outcomes are not shared, are strictly preferred to those that are aggregate, where they are shared. Another way of explaining this is that what matters biologically is not absolute success in producing offspring, but success relative to other types. In the above example, although the offspring distributions for the two types are the same from an individual point of view, the private-coin type grows as a fraction of the population. This is because, as a ratio (even though not in absolute terms), it outdoes the public-coin type, when the public coin comes up heads, by more than enough to compensate for how much it falls behind when the public coin comes up tails. Indeed, in the first period, the ratio of the private-coin type's offspring to that of the public-coin type is $3 / 2$ for heads, but $3 / 4$ for tails. Over any number of periods, this ratio of the two types is then determined as the product of as many $3 / 2 \mathrm{~s}$ as there were heads for the public coin and as many $3 / 4 \mathrm{~s}$ as there were tails. Since heads and tails are equally likely, and $(3 / 2)(3 / 4)=9 / 8>$ 1 , the private-coin type dominates the public-coin type in the long run. ${ }^{10}$

This argument can be translated into economic preferences that are no longer purely selfish, but are interdependent in a particular sense. Hence, an evolutionary perspective suggests a direction for extending the standard economic perspective on uncertainty. This analysis may illuminate why individuals seem more averse to aggregate risks-such as those entailed by "mad cow disease," say, where the causal mechanism remains unclear-than they are to idiosyncratic risks-such as that from heart disease, say. In any case, this theoretical distinction invites empirical testing.

The argument that attitudes toward risk are interdependent seems an unexpected exception to the general emphasis here on the individual as the focus of

\footnotetext{
${ }^{8}$ Enormous population sizes may still be more likely for the public-coin type than for the private-coin type. If the aim were to reach a target population level, one that could be reached only with a small probability in the time allowed, the public-coin type might be favored.

${ }^{9}$ The size of the public-coin type after $T$ periods is exactly $2^{n(T)}$, where $n(T)$ is the number of tails in $T$ flips of a fair coin. The average per period growth factor, $g$, over these $T$ periods then satisfies $g^{T}=$ $2^{n(T)}$, so that $g=2^{n(T) / T}$. Since $n(T) / T \rightarrow 1 / 2$ as $T \rightarrow \infty$, by the law of large numbers, it follows that this average growth factor converges to $2^{1 / 2}=\sqrt{2}<3 / 2$. Thus, the average per period growth factor of the public-coin type converges to a value that is strictly less than the constant per period growth factor of the private-coin type. This implies that the ratio of the number of the private-coin type to that of the public-coin type tends to infinity with probability one, to be precise.

${ }^{10}$ If there is only aggregate risk, an appropriate criterion for evolutionary success is the expected logarithm of offspring in each state. Blume and Easley (1992) present an analogous argument in an asset market setting implying that logarithmic utility of wealth would be evolutionarily favored.
} 
biological fitness. It certainly illustrates how slippery the distinctions among the levels of the gene, the individual and the group can be. Consider the present result from the most basic viewpoint, that of the gene. Each gene is present in a large group of individuals, and the most successful gene is the one that most effectively promotes the size of its group in the face of the idiosyncratic and aggregate risk. Thus, taking the basic viewpoint of the gene as the focus of biological fitness produces interdependent preferences, a result that might seem philosophically more consistent with the polar opposite viewpoint of the group.

\section{Utility as Adaptive in the Long Run}

The usual assumption in economics is that preferences are exogenous and unchanging. A biological approach would seem likely to support this approach. However, this implication is less clear than it may seem. In the first place, even if utility functions are immutable over the individual's lifetime, these utility functions were shaped by the environment in which the individual's species evolved. In the second place, utility may optimally adapt during the lifetime of the individual. Long-run adaptation is considered in the present section, whereas short-run adaptation is the topic of the next.

There is evidence that the evolutionary environment shaped preferences. For example, most animals have the ability to synthesize vitamin $\mathrm{C}$ internally. Human beings, however, lack this ability, relying instead on our consumption of plant food throughout our evolutionary history. (For a short accessible discussion, see "vitamin C" in the Encyclopedia Britannica.) If the capacity to synthesize vitamin C entailed a metabolic cost, it might have paid to lose this capacity. More plausibly, perhaps, given that many other species that eat plants have not lost this capacity, the metabolic cost was small, and the loss resulted from a mutation with a negligible fitness advantage. In any case, an individual with the ability to synthesize vitamin $\mathrm{C}$ has different preferences from one without, with the latter having a more urgent need to consume plants. The availability of plants throughout the evolutionary history of our species then encouraged, or at least allowed, an evolved preference for plants.

To take another example, the ability to store food internally-as body fat, for example-might affect attitudes toward risk. Consider an animal with a particular ability to convert current energy into current expected offspring. Suppose that the "fitness function" linking current energy and current expected offspring is increasing, but has diminishing marginal product. Take overall expected offspring as the undiscounted sum of the fitness functions for each period. Suppose that this animal confronts a situation in which food arrives in random amounts. If food can be stored internally and carried forward, to be used at times when no food is available, then this animal can increase its expected total number of offspring. Even if storage involves a metabolic cost, storage will still be favored if this cost is small enough.

The ability to store food would also alter the criterion used to evaluate risk, 
since the effect of storage is to spread consumption out more equally over the fitness functions. With two periods, where the random amount of food arrives in the first period, it can be shown that risk aversion decreases as a result of storage if the fitness function has increasing relative risk aversion. Risk aversion increases, on the other hand, when the fitness function has decreasing relative risk aversion. ${ }^{11}$

More specifically, many carnivorous species have an ability to maintain glucose stores for an extended period of time. Thus, even if animals from these species have not fed for several days, they retain an instant energy source for their muscles and so can capture prey when the opportunity arises. An ability to store glucose seems less marked in humans, on the other hand, perhaps because we evolved from species that relied on plant food and so experienced less variability in food supply. The availability of a new predatory niche for humans, combined with our inability to tolerate the consequent uncertain food supply, would then have fostered the formation of hunting and gathering societies to share food. Once hunter-gatherer societies were formed, and the food supply to individuals could then be smoothed out over time, the evolutionary pressure toward predatory physiological adaptations like glucose storage would have been reduced. This human trait also suggests why the need to manage risk in the food supply could have been a strong force holding human societies together, although this force was at the same time weak for other predatory species.

\section{Utility as Adaptive in the Short Run}

Intriguing studies have been done in which people are asked to estimate their own level of happiness (for example, Scitovsky, 1992, chapter 7). A common finding in these studies is that people tend to respond according to their rank in their society at that point in time. Those in the middle class at earlier dates, perhaps several decades earlier, often rank themselves as being as happy as those who are in the middle class at later dates-even though consumption levels and life prospects appear to be far worse several decades ago. If these self-reported estimates of individual happiness, while obviously imprecise, are nonetheless meaningful to some extent, what should be made of the fact that these estimates are at least partly

\footnotetext{
${ }^{11}$ Suppose the fitness function in each of the two periods is $u(c)$, where $u$ is increasing and concave. There is no discounting, and $u(0)=0$. A random amount of food, $\tilde{w}$, is available in the first period. Without storage, total expected fitness is then $E u(\tilde{w})$. Suppose now that any amount of food can be stored at a fixed cost, $F$. The optimal amount of food to carry forward is $\tilde{w} / 2$, and total expected fitness is now $2 E u(\tilde{w} / 2)-F$. Storage is then advantageous if and only if $2 E u(\tilde{w} / 2)-F>E u(\tilde{w})$, which must hold whenever $F$ is small enough, given the conditions on $u$.

Consider then the effect of food storage on risk aversion. If $V(w)=2 u(w / 2)-F$, the coefficient of relative risk aversion for $V$ is less than this coefficient for $u$, if the coefficient of relative risk aversion for $u$ is increasing. This is because this latter condition implies that $-\left(w V^{\prime \prime}(w) / V^{\prime}(w)\right)=-((w)$ 2) $\left.u^{\prime \prime}(w / 2) / u^{\prime}(w / 2)\right)<-\left(w u^{\prime \prime}(w) / u^{\prime}(w)\right)$. Indeed, since $-\left(V^{\prime \prime}(w) / V^{\prime}(w)\right)<-\left(u^{\prime \prime}(w) / u^{\prime}(w)\right)$, storage reduces risk aversion in terms of the coefficient of absolute risk aversion, also. The argument if $u$ has decreasing relative risk aversion is analogous.
} 
relative? Surely this creates difficulty for consumer theory. Analogously, a median individual in a poorer country would have a similar level of utility to the median individual in a richer country. Thus, standard theory implausibly predicts that such an individual in a poor society would reject a transition to a situation slightly below the median in a richer society, even though the change might offer a much higher level of consumption.

Possessing utility that has a relative and local scale, rather than an absolute or global scale, may be biologically advantageous, and the behavior induced may differ to only a limited extent from that in the usual economic model. The issue may be analogous to the use of a voltmeter. To obtain an accurate reading from this device, it is necessary to first estimate the range in which the unknown voltage falls. Only if the right range is selected on the device, such that the needle moves to the middle of the scale, is an accurate reading obtained.

Analogously, an individual may have a limited set of internal mental states to register the desirability of consumption bundles, where these states might be experienced as varying intensities of pleasure. For simplicity and specificity, suppose that an individual has a single threshold value for fitness. If the actual underlying fitness is less than the threshold, the situation is perceived as "bad"; otherwise, it is perceived as "good." In this case, the individual utility function then lumps all choices into two groups- "good" and "bad"-and can only distinguish between two choices if one is good and the other is bad. If the individual only ever faced a single choice situation, where a particular consumption choice was best, it would be optimal to set the threshold just below the fitness of the best choice. In this way, the individual would perceive all suboptimal choices as bad and only the optimal choice as good. In a more favorable situation, where the optimal choice offers a higher level of fitness, the optimal threshold value should be correspondingly higher. It is optimal for the utility function to adapt in this way.

This example is obviously special in a number of ways. For example, it is special in assuming there is a single maximization problem so that the threshold can be customized to this problem. More realistically, if the maximization problem were itself drawn from some distribution, the optimal threshold would represent an appropriate compromise over the entire range of problems. In addition, it would be more general to have a number of threshold values, where these should be spaced out in a fashion that is optimal for the distribution of problems to be addressed. Neither of these considerations seems to affect the basic conclusion that the threshold values and, hence, utility should adapt to the choice environment.

This analysis may shed light on why individuals in richer countries do not typically report higher levels of "happiness" than do those in poorer ones. That is, utility should adapt so that only the choices that must be made in each environment are dealt with appropriately. Without such a suitable adaptive property, moreover, evolution could never have shaped preferences over, for example, amounts of money that were wildly infeasible over most of evolutionary history.

This discussion derives a number of implications of evolutionary theory for 
preferences. It seems plausible that evolution would generate a utility function over consumption bundles, thus reinforcing the conventional economic model. For dynamic choice, furthermore, an evolutionary approach favors time consistency, a basic property shared by a variety of conventional treatments, but not by "hyperbolic discounting," where the discount rate in the near future is higher than in the more distant future. On the other hand, for decision making under uncertainty, an evolutionary approach suggests a novel form of nonexpected utility involving interdependent preferences. Moreover, the utility function in modern individuals reflects an evolutionary adaptation to the typical circumstances during human evolution. In the short run, adaptation might also be expected, thus illuminating empirical observations that otherwise seem awkward.

\section{Beliefs}

People do not choose only among consumption bundles, but, more generally, among probability distributions over consumption bundles. Beliefs are the probabilities with which individuals think that various consumption bundles will occur. If many alternative consumption bundles can arise with a particular probability, perhaps because this is the probability of a particular identifiable state, it might be cost-effective to embed this probability in the individual. The argument is parallel and supplementary to the case made earlier for assigning utility levels to consumption bundles.

This argument applies if the probability distributions, as well as the consumption bundles, are constant. More often, perhaps, there is an asymmetry between consumption bundles and probability distributions. It is plausible to believe that the fitness consequences of consumption may have been stable for a long time, so that Nature's information on these is superior to that of the individual. In the case of beliefs, however, matters may be reversed, in that the individual has superior local information about the particular probability distribution in effect over consumption bundles.

Suppose that an individual faces a choice between two actions, $a$ and $b$, where this choice is repeated many times. Prior to making this choice, one of two signals, $s$ or $t$, is observed. There are two underlying states of the world that change occasionally during the lifetime of an individual. In state I, action $a$ is optimal when the signal is $s$, and action $b$ is optimal when the signal is $t$; in state II, the two signals have the reverse implications. Clearly, evolution cannot build in either automatic response to the two signals; equally clearly, it is easy for an individual to learn the correct response to each signal.

This example is essentially the classic Pavlovian model of associative learning from psychology. Dogs famously were trained to salivate at the sound of a bell, since this signal was arranged by the experimenter to precede the arrival of food. The dogs had no difficulty in forming this association, despite its arbitrary nature. After 
hearing the bell, the dogs believe that food is on the way, where "belief" can be given a concrete operational meaning. Although animals are not the blank slates that psychologists once claimed, the ability to form such associations is widespread. Indeed, some associative learning can occur at the level of the neuron, and so beliefs here need not be conscious. Greater intelligence, however, would permit the formation of beliefs to be more rapid and accurate in complex settings.

The optimal design strategy for Nature may then be to link consumption to utility (since on this issue, Nature has better information), but at the same time to allow for the flexible and intelligent modification of beliefs (since in this case, the local information of the individual may be superior). In terms of the principalagent metaphor, it may pay for the principal to impose the appropriate preferences, but at the same time to design the agent to be capable of independent beliefs and, ultimately, action.

In a broad sense, the present biological view of preferences, beliefs and rationality supports the conventional approach. However, rationality is bound to be incomplete and the updating of beliefs inexact. The biological basis for bounded rationality is not a topic on which there is a great deal of work, however, and so the following section is also preliminary in nature. ${ }^{12}$

\section{Rationality}

There are two main hypotheses in the biological and psychological literature concerning the evolution of human intelligence. The first of these, the "ecological hypothesis," is that the impetus came from interactions with the nonhuman environment-the need to obtain food and to avoid predators, for example. This hypothesis essentially derives the biological characteristic of human intelligence from the operation of a primitive economy.

Kaplan and Robson (2001), for example, explain why intelligence and longevity were simultaneously exaggerated in the hunter-gatherer societies that are believed to have characterized the overwhelming majority of the two million years of human evolutionary history. Observations on modern hunter-gatherers suggest that a huge intertemporal economic tradeoff over the life span distinguished humans from most other species. When they are young, individuals consume much more than they produce, but this debt is repaid with interest during adulthood with a large-flow surplus. Net food production data from anthropological field studies of the Ache of Paraguay, the Hiwi of Venezuela and the Hadza of Tanzania, for example, are summarized in Figure 1, adapted

\footnotetext{
12 There is a substantial body of psychological evidence of systematically irrational economic behavior by individuals (for example, Kahneman, Slovic and Tversky, 1982). These phenomena have inspired a small research literature in economics providing "top-down" evolutionary rationales (for example, Waldman, 1994).
} 


\section{Figure 1}

\section{Net Food Production for Human Foragers}

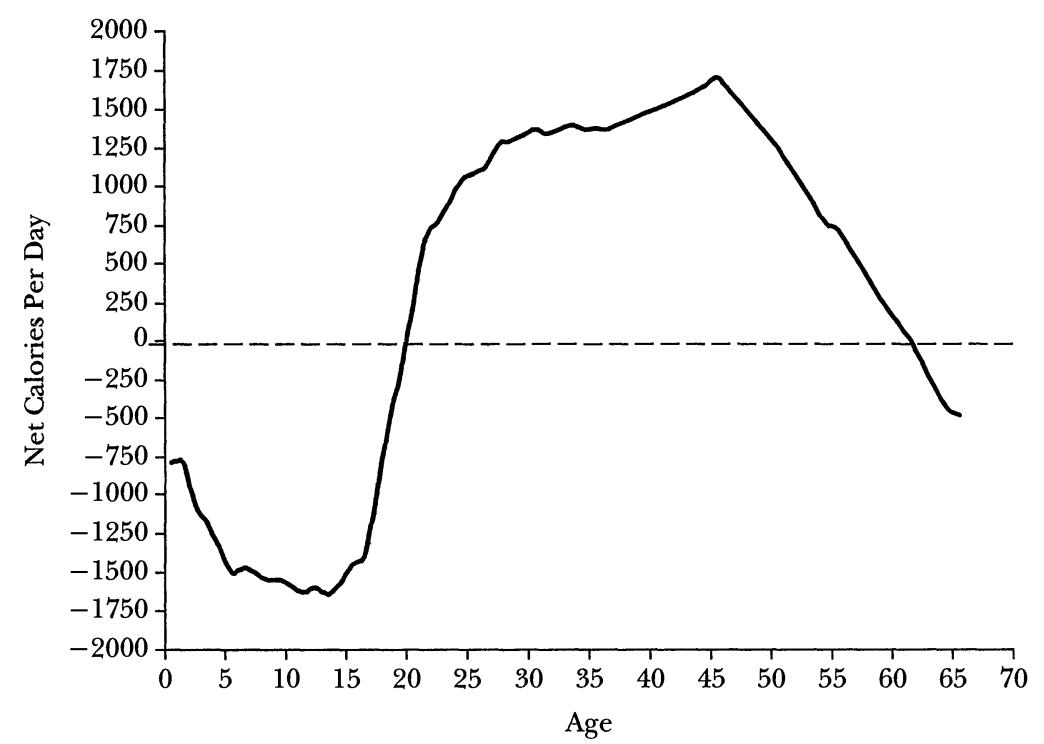

Source: Adapted from Kaplan and Robson (2001).

from Kaplan and Robson (2001). These groups, whose ancient structure persisted into the twentieth century, present rare opportunities for detailed views of the culminating economy and life history of hunting and gathering.

The huge intertemporal lifetime tradeoff is a reflection of the highly skill-intensive nature of human hunting and gathering. There is a long period of learning during which net output is negative. But once this learning is complete, the reward is the greatly enhanced production of animal and plant foods. To push the argument further back, the learning involved in this economic life-cycle strategy is only possible given the phenomenal enlargement of the brain that is perhaps the most fundamental characteristic of humans.

Indeed, the archeological evidence is unambiguous that human brain size has increased dramatically during the two million years of our evolutionary history. This growth seems to have occurred together with a substantial increase in longevity. Indirect evidence, for example, suggests that our immediate evolutionary predecessor (Australopithecus) had a life span of 35-40 years, comparable to that of the modern chimpanzee. On theoretical grounds, intelligence and longevity should be tied together like this. Indeed, an analogous model suggests that modern individuals who invest heavily in human capital would 
tend also to have large expenditures on health maintenance, as seems to be a plausible prediction. ${ }^{13}$

The second main hypothesis about the evolution of intelligence is that of social, or Machiavellian, intelligence (for example, Byrne and Whiten, 1988). This appealing idea is that strategic interactions with other humans provided the key impetus toward greater intelligence. Such pressure might have occurred in an arms race fashion, if what matters is not how smart I am in absolute terms, but rather whether I am smarter than you are. Another interesting aspect of this is the so-called "theory of mind," concerning the capacity to anticipate one another's desires and beliefs, as at issue in game theory (Leslie, 1987).

Why might such a capacity for social intelligence have evolved? When people make decisions, for example, it is often useful for them to know how others will respond. One possibility is for each person to know the preferred option from each pair of alternatives for each other person. But this may be expensive. If each person, instead, has the utility function for each other agent embedded in her mind, this may well be a cheaper way to account for the preferences of others. That is, it is advantageous for me to use the same procedure to predict your choice that you use to generate it.

An ultimate goal for considering the evolution of rationality would be to derive predictions as to how exactly it is bounded. Most of this work remains to be done, but it is of interest that the theory of mind suggests that individuals would be more rational in competitive social interactions than they are in more abstract settings (for example, Cosmides, 1989).

\section{Conclusions}

There are a vast number of promising avenues for further investigation of how biological evolution may have affected preferences, beliefs and rationality. The brief treatment of beliefs and rationality here reflects the lack of much previous work on these topics. The evolution of rationality is, in particular, a promising but challenging topic for more research. The conventional economic assumption here is so strong that appropriate relaxation of it is bound to pay considerable dividends.

In the better trodden field of the evolution of preferences, there remain interesting issues, which may also be more tractable. Just to pick one, if utility is adaptive to the environment in the short run, it needs to be understood in greater detail how this process of adaptation is generated. Perhaps at the same time that a relative utility scale is used to evaluate outcomes, these outcomes also modify the

\footnotetext{
${ }^{13}$ Kaplan and Robson (2001) outline the analogy to a model of health care and human capital. Ehrlich and Chuma (1990) make the related argument that greater financial wealth generates greater health expenditures and hence greater longevity.
} 
utility scale. The actual process of adaptation could be still more complex than this, however, if the mere anticipation of favorable events in the future changes the present utility scale, for example.

An evolutionary approach to preferences, beliefs and rationality holds great promise. It may allow or suggest extensions of economic theory to account for more phenomena; consider, for example, the evaluation of risk with interdependent preferences. At the same time, it suggests that certain generalizations of preferences are less likely because they do not fit well with evolutionary explanationsalthough it will always be necessary to be careful about what constitutes a reasonable evolutionary explanation. An insistence on theoretical generality and attention to anthropological observations on hunter-gatherer societies will help to discriminate among such explanations.

- I appreciate research support from the Social Sciences and Humanities Research Council of Canada and from a Canada Council Killam Research Fellowship. I also thank Brad De Long, Hilly Kaplan, Timothy Taylor and Mike Waldman for helpful comments.

\section{References}

Angeletos, George-Marios et al. 2001. "The Hyperbolic Consumption Model: Calibration, Simulation, and Empirical Evaluation." Journal of Economic Perspectives. Summer, 15:3, pp. 47-68.

Bergstrom, Theodore C. 1996. "Economics in a Family Way." Joumal of Economic Literature. December, 34:4, pp. 1903-934.

Byrne, Richard W. and Andrew Whiten. 1988. Machiavellian Intelligence: Social Expertise and the Evolution of Intellect in Monkeys, Apes, and Humans. Oxford: Oxford University Press.

Blume, Lawrence and David Easley. 1992. "Evolution and Market Behavior." Journal of Economic Theory. October, 58:1, pp. 9-40.

Cavalli-Sforza, L.L. and W.F. Bodmer. 1999. The Genetics of Human Populations. Mineola, N.Y.: Dover.

Cosmides, Leda. 1989. "The Logic of Social Exchange: Has Natural Selection Shaped How Humans Reason? Studies with the Wason Selection Task." Cognition. April, 31:3, pp. 187-276.

Dawkins, Richard. 1982. The Extended Phenotype: The Gene as the Unit of Selection. Oxford: Oxford University Press.
Ehrlich, Isaac and Hiroyuki Chuma. 1990. "A Model of the Demand for Longevity and the Value of Life Extension." Journal of Political Economy. August, 98:4, pp. 761-82.

Gabaix, Xavier and David Laibson. 2000. "Bounded Rationality and Directed Cognition." Harvard University Working Paper.

Kahneman, Daniel, Paul Slovic and Amos Tversky. 1982. Judgment Under Uncertainty: Heuristics and Biases. Cambridge: Cambridge University Press.

Kaplan, Hillard S. and Arthur J. Robson. 2001. "The Evolution of Human Longevity and Intelligence in Hunter-Gatherer Economies." University of Western Ontario Working Paper.

Le Doux, Joseph. 1996. The Emotional Brain: The Mysterious Underpinnings of Emotional Life. New York: Touchstone.

Leslie, Alan M. 1987. "Pretense and Representation: The Origins of "Theory of Mind." Psychological Review. 94:4, pp. 412-26.

Loewenstein, George and Drazen Prelec. 1992. "Anomalies in Intertemporal Choice: Evi- 
dence and an Interpretation." Quarterly Journal of Economics. May, 107:2, pp. 573-97.

Machina, Mark. 1982. “'Expected Utility’ Analysis without the Independence Axiom." Econometrica. March, 50, pp. 277-323.

Robson, Arthur J. 1996. "A Biological Basis for Expected and Non-Expected Utility." Jourmal of Economic Theory. February, 68:2, pp. 397-424.

Robson, Arthur J. 2001a. "The Biological Basis of Economic Behavior." Joumal of Economic Literature. March, 39:1, pp. 11-33.

Robson, Arthur J. 2001b. "Why Would Nature Give Individuals Utility Functions?" Joumal of Political Economy. August, 109:4, pp. 900-14.
Rogers, Alan. 1994. "Evolution of Time Preference by Natural Selection." American Economic Review. June, 84:3, pp. 460-81.

Samuelson, Larry and Jeroen Swinkels. 2000. "Sex, Cashews and Evolution." University of Wisconsin Working Paper.

Scitovsky, Tibor. 1992. The Joyless Economy. Oxford: Oxford University Press.

Strotz, Robert. 1956. "Myopia and Inconsistency in Dynamic Utility Maximization." Review of Economic Studies. 23:3, pp. 165-80.

Waldman, Michael. 1994. "Systematic Errors and the Theory of Natural Selection." American Economic Review. June, 84:3, pp. 482-97. 
http://www.jstor.org

\title{
LINKED CITATIONS
}

\author{
- Page 1 of 4 -
}

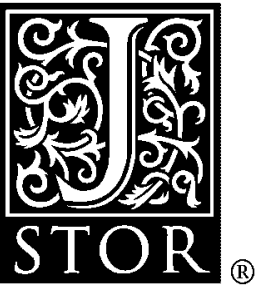

You have printed the following article:

\section{Evolution and Human Nature}

Arthur J. Robson

The Journal of Economic Perspectives, Vol. 16, No. 2. (Spring, 2002), pp. 89-106.

Stable URL:

http://links.jstor.org/sici?sici=0895-3309\%28200221\%2916\%3A2\%3C89\%3AEAHN\%3E2.0.CO\%3B2-4

This article references the following linked citations. If you are trying to access articles from an off-campus location, you may be required to first logon via your library web site to access JSTOR. Please visit your library's website or contact a librarian to learn about options for remote access to JSTOR.

\section{[Footnotes]}

\author{
${ }^{1}$ The Biological Basis of Economic Behavior \\ Arthur J. Robson \\ Journal of Economic Literature, Vol. 39, No. 1. (Mar., 2001), pp. 11-33. \\ Stable URL: \\ http://links.jstor.org/sici?sici=0022-0515\%28200103\%2939\%3A1\%3C11\%3ATBBOEB\%3E2.0.CO\%3B2-8

\section{${ }^{3}$ Economics in a Family Way} \\ Theodore C. Bergstrom \\ Journal of Economic Literature, Vol. 34, No. 4. (Dec., 1996), pp. 1903-1934. \\ Stable URL: \\ http://links.jstor.org/sici?sici=0022-0515\%28199612\%2934\%3A4\%3C1903\%3AEIAFW\%3E2.0.CO\%3B2-M
}

\author{
${ }^{4}$ Why Would Nature Give Individuals Utility Functions? \\ Arthur J. Robson \\ The Journal of Political Economy, Vol. 109, No. 4. (Aug., 2001), pp. 900-914. \\ Stable URL: \\ http://links.jstor.org/sici?sici=0022-3808\%28200108\%29109\%3A4\%3C900\%3AWWNGIU\%3E2.0.CO\%3B2-Y

\footnotetext{
${ }^{6}$ Evolution of Time Preference by Natural Selection

Alan R. Rogers

The American Economic Review, Vol. 84, No. 3. (Jun., 1994), pp. 460-481.

Stable URL:

http://links.jstor.org/sici?sici=0002-8282\%28199406\%2984\%3A3\%3C460\%3AEOTPBN\%3E2.0.CO\%3B2-P
}

NOTE: The reference numbering from the original has been maintained in this citation list. 
http://www.jstor.org

\section{LINKED CITATIONS}

- Page 2 of 4 -

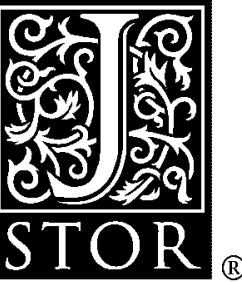

${ }^{7}$ The Hyperbolic Consumption Model: Calibration, Simulation, and Empirical Evaluation George-Marios Angeletos; David Laibson; Andrea Repetto; Jeremy Tobacman; Stephen Weinberg The Journal of Economic Perspectives, Vol. 15, No. 3. (Summer, 2001), pp. 47-68.

Stable URL:

http://links.jstor.org/sici?sici=0895-3309\%28200122\%2915\%3A3\%3C47\%3ATHCMCS\%3E2.0.CO\%3B2-5

${ }^{12}$ Systematic Errors and the Theory of Natural Selection

Michael Waldman

The American Economic Review, Vol. 84, No. 3. (Jun., 1994), pp. 482-497.

Stable URL:

http://links.jstor.org/sici?sici=0002-8282\%28199406\%2984\%3A3\%3C482\%3ASEATTO\%3E2.0.CO\%3B2-J

${ }^{13}$ A Model of the Demand for Longevity and the Value of Life Extension Isaac Ehrlich; Hiroyuki Chuma

The Journal of Political Economy, Vol. 98, No. 4. (Aug., 1990), pp. 761-782.

Stable URL:

http://links.jstor.org/sici?sici=0022-3808\%28199008\%2998\%3A4\%3C761\%3AAMOTDF\%3E2.0.CO\%3B2-W

\section{References}

The Hyperbolic Consumption Model: Calibration, Simulation, and Empirical Evaluation George-Marios Angeletos; David Laibson; Andrea Repetto; Jeremy Tobacman; Stephen Weinberg The Journal of Economic Perspectives, Vol. 15, No. 3. (Summer, 2001), pp. 47-68.

Stable URL:

http://links.jstor.org/sici?sici=0895-3309\%28200122\%2915\%3A3\%3C47\%3ATHCMCS\%3E2.0.CO\%3B2-5

\section{Economics in a Family Way}

Theodore C. Bergstrom

Journal of Economic Literature, Vol. 34, No. 4. (Dec., 1996), pp. 1903-1934.

Stable URL:

http://links.jstor.org/sici?sici=0022-0515\%28199612\%2934\%3A4\%3C1903\%3AEIAFW\%3E2.0.CO\%3B2-M

NOTE: The reference numbering from the original has been maintained in this citation list. 
http://www.jstor.org

\title{
LINKED CITATIONS
}

- Page 3 of 4 -

\author{
A Model of the Demand for Longevity and the Value of Life Extension \\ Isaac Ehrlich; Hiroyuki Chuma \\ The Journal of Political Economy, Vol. 98, No. 4. (Aug., 1990), pp. 761-782. \\ Stable URL: \\ http://links.jstor.org/sici?sici=0022-3808\%28199008\%2998\%3A4\%3C761\%3AAMOTDF\%3E2.0.CO\%3B2-W
}

\author{
Anomalies in Intertemporal Choice: Evidence and an Interpretation \\ George Loewenstein; Drazen Prelec \\ The Quarterly Journal of Economics, Vol. 107, No. 2. (May, 1992), pp. 573-597. \\ Stable URL: \\ http://links.jstor.org/sici?sici=0033-5533\%28199205\%29107\%3A2\%3C573\%3AAIICEA\%3E2.0.CO\%3B2-\%23
}

\author{
"Expected Utility" Analysis without the Independence Axiom \\ Mark J. Machina \\ Econometrica, Vol. 50, No. 2. (Mar., 1982), pp. 277-323. \\ Stable URL: \\ http://links.jstor.org/sici?sici=0012-9682\%28198203\%2950\%3A2\%3C277\%3A\%22UAWTI\%3E2.0.CO\%3B2-V
}

\section{The Biological Basis of Economic Behavior}

Arthur J. Robson

Journal of Economic Literature, Vol. 39, No. 1. (Mar., 2001), pp. 11-33.

Stable URL:

http://links.jstor.org/sici?sici=0022-0515\%28200103\%2939\%3A1\%3C11\%3ATBBOEB\%3E2.0.CO\%3B2-8

\section{Why Would Nature Give Individuals Utility Functions?}

Arthur J. Robson

The Journal of Political Economy, Vol. 109, No. 4. (Aug., 2001), pp. 900-914.

Stable URL:

http://links.jstor.org/sici?sici=0022-3808\%28200108\%29109\%3A4\%3C900\%3AWWNGIU\%3E2.0.CO\%3B2-Y

\section{Evolution of Time Preference by Natural Selection}

Alan R. Rogers

The American Economic Review, Vol. 84, No. 3. (Jun., 1994), pp. 460-481.

Stable URL:

http://links.jstor.org/sici?sici=0002-8282\%28199406\%2984\%3A3\%3C460\%3AEOTPBN\%3E2.0.CO\%3B2-P

NOTE: The reference numbering from the original has been maintained in this citation list. 
http://www.jstor.org

\section{LINKED CITATIONS \\ - Page 4 of 4 -}

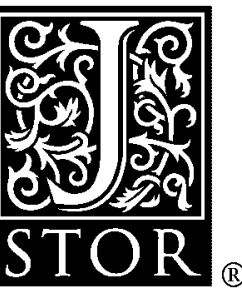

\section{Myopia and Inconsistency in Dynamic Utility Maximization}

R. H. Strotz

The Review of Economic Studies, Vol. 23, No. 3. (1955 - 1956), pp. 165-180.

Stable URL:

http://links.jstor.org/sici?sici=0034-6527\%281955\%2F1956\%2923\%3A3\%3C165\%3AMAIIDU\%3E2.0.CO\%3B2-\%23

\section{Systematic Errors and the Theory of Natural Selection}

Michael Waldman

The American Economic Review, Vol. 84, No. 3. (Jun., 1994), pp. 482-497.

Stable URL:

http://links.jstor.org/sici?sici=0002-8282\%28199406\%2984\%3A3\%3C482\%3ASEATTO\%3E2.0.CO\%3B2-J

NOTE: The reference numbering from the original has been maintained in this citation list. 